\title{
EVENTOS GASTRONÓMICOS EN MÉXICO Y TURISMO
}

\section{GASTRONOMIC EVENTS IN MEXICO AND TOURISM}

Mónica Isabel Mejía Rocha*

* Doctora en Ciencias Administrativas. Profesora Investigadora. Universidad de Guanajuato.

Dirección para recibir correspondencia: monicamejia@ugto.mx 


\section{RESUMEN}

La historia culinaria mexicana es opulenta a través de la cual se puede apreciar desde la historia prehispánica, así como el mestizaje con otras culturas. La gastronomía como tal alude a la cultura, esencia y espíritu de los pueblos. La cultura prehispánica como tal, sienta sus bases en cuatro elementos principales: el maíz, el chile, el frijol y el cacao. El presente trabajo permite mostrar al lector el inventario de los diferentes eventos gastronómicos que se desarrollan en la República Mexicana a fin de promover la cultura y fortalecer los productos turísticos que ofrecen los destinos nacionales. Dentro de los principales resultados se pudo conocer que existe una variedad significativa en cuanto a las ferias, festivales y encuentros gastronómicos en el país. Estos eventos no siempre aluden a insumos endémicos de la región donde se promueven; sin embargo, si todos se presumen benefician al desarrollo de la actividad turística.

PALABRAS CLAVE: Turismo. Eventos gastronómicos. Oferta. Endémicos.

\section{ABSTRACT}

The Mexican culinary history is opulent and is a means to appreciate from pre-Hispanic history, as well as mestizaje with other cultures. Gastronomy itself alludes to the culture, essence, and spirit of the people. The pre-Hispanic culture itself sets its bases on four main elements: maize, chile, beans and cacao. The present work allows showing to the reader the inventory of the different gastronomic events that are held in the Mexican Republic in order to promote the culture and strengthen the tourist products that offer the national destinations. Among the main results it was possible to know that there is a significant variety in terms of fairs, festivals and gastronomic meetings in the country. These events do not always refer to endemic inputs from the region where they are promoted.

KEY WORDS: Tourism. Gastronomic events. Offer. Endemic. 


\section{INTRODUCCIÓN}

La gastronomía en México es el resultado de la cultura de un pueblo que refleja su ambiente, su tradición, los ingredientes, el contexto social que lo envuelve, cultural, pero también hay algo importante que se llama conocimiento tradicional.

El conocimiento tradicional o espacito que se transmite de generación en generación, el mundo prehispánico, se dice que tiene como elementos culturales en su historia identificados el maíz, el chile, el frijol y el cacao; el maíz es un alimento que era venerado por los nahuas, vinculado a Quetzalcóatl y también se decía que era la gracia de Dios; hay algunas leyendas que dicen que venimos del maíz.

Intentando identificar un poco el valor que se le daba al maíz como tal, se ha registrado hasta el día de hoy y a lo largo de la historia, más o menos 22 clases distintas de maíz en México. El frijol como tal también es un grano, una semilla que se consume desde la época prehispánica en México, de este existen más o menos 70 variedades de frijol, se dice que actualmente sienta fuertemente las bases de la comida mexicana.

Actualmente, los Estados que mayormente producen el frijol son Durango, Sinaloa y Zacatecas, el chile bueno como tal no se encuentra, aún no se ha sido posible determinar a precisión su origen, aunque también Mesoamérica era un continente en que se utilizaba mucho, cuando descubre el nuevo mundo Cristóbal Colón, que hacía referencia en sus primeros códices donde hablaba de lo que había descubierto, decía que el chile es pimiento de las Indias, fue tal su importancia del chile que se ha empleado en rituales religiosos ya que existía una diosa del chile.

El cacao como tal fue apreciado por reyes náhuatl y nobles, base de los condimentos, además de un guiso mestizo como lo es el mole. Dentro de los platillos más significativos que se pueden encontrar a partir de estos cuatro elementos se encuentran: los sopes, pellizcadas, tamales, chocolate, pozole, tacos, chiles en nogada, otro tipo de tamal, huaraches, las tortillas de color, atole a base de maíz, tostadas, entre otros. Lo anterior, refleja la manera en la que se continúa utilizando hasta nuestros días la cocina ancestral, reflejo de esto, es el conocimiento tradicional heredado de generaciones en generaciones.

El turismo en México representa el 8.7\%; es decir, muy cerca de lo que es a nivel mundial, genera 2.3 millones de empleos, lo cual representa el 1\%, de personas empleadas a nivel nacional. Casi el 10\% lo emplea el turismo en México, y permite favorablemente la participación, bueno en México todavía esto es a inicios y finales del año pasado, las mujeres, la participación en el plano turístico en México, es del 54.8, casi el 55\%. 
El Código de Ética del Turismo en su artículo 3, permite el desarrollo sostenible para las comunidades donde se trate; la gastronomía como tal lo permite y lo promueve, para que prevalezcan las culturas y las tradiciones de un pueblo y fortalecer la gastronomía. Mientras que la "Agenda 21 para el turismo mexicano", también habla de proponer estrategias y acciones que permitan el desarrollo sustentable; es decir, que involucre a las sociedades en donde se da el turismo, el Plan de Desarrollo Nacional (PDN).

La gastronomía dentro de la planificación de desarrollo turístico, es un elemento importante y diferenciador para México. Asimismo, parte de la gastronomía del país forma parte del catálogo del Patrimonio Mundial de la UNESCO.

Se estima que el 30\% del gasto ejercido en el turismo a nivel internacional, los turistas internacionales que llegan a México, corresponde a la parte de alimentos, la industria de preparación representa el $10 \%$ en el componente de lo que representa la actividad turística como tal, entonces si ponemos en la media los servicios turísticos, lo que es la preparación, venta y distribución de alimentos, también tiene un valor relevante dentro del Producto Interno Bruto, emplea a 1.4 millones de personas y cuentan con 515 mil establecimientos (DENUE INEGI).

Los eventos o ferias gastronómicas refieren a los espacios en un tiempo determinado en donde se convoca la asistencia de productores y visitantes para dar a conocer y consumir platillos y bebidas alusivas alguna cultura o gastronomía determinadas. Dentro de las ventajas principales, se puede observar que estos eventos pueden ser considerados como herramientas de promoción que facilitan el desarrollo y consolidación de destinos a través de la oferta cultural complementaria que proponen este tipo de actividades y que además pueden contrarrestar el efecto de "estacionalidad" dentro de la actividad turística.

\section{MATERIAL Y MÉTODO}

El presente trabajo de investigación tiene como finalidad a través del método de análisis documental y de fuentes de información electrónicas identificar y establecer un catálogo enunciativo sobre los eventos gastronómicos que se lleven a cabo actualmente en el territorio mexicano, a fin de fortalecer el desarrollo de la actividad turística. Se realizó un análisis de los eventos identificados a fin de determinar sus características y temporalidad en la que se realizan dichos eventos. 


\section{RESULTADOS}

Existen una gran variedad de festivales, ferias y eventos gastronómicos en México (ver tabla 1), es un tanto la diferencia de establecimientos de alimentos o preparación y venta de alimentos, estos eventos gastronómicos tienen más bien la intención de fortalecer el valor de la cultura a través de la gastronomía. Este tipo de eventos se desarrolla cada vez más al interior de la República Mexicana (ver figura 1).

El turista actual, en esta era del conocimiento y de la información, no sólo basta con viajar sino conocer más del lugar al que llega, ya no es un turista pasivo, ahora es un turista dinámico, que quiere aprovechar al máximo; por ello, aunque la economía a nivel mundial esté deteriorada y exista escasez, la necesidad de viaje, de traslado, de ocio, sigue existiendo en las personas; es decir, el turismo gastronómico también promueve otra de las cosas que se busca y que es el turismo doméstico o el turismo interno.

Tabla 1

Eventos gastronómicos en México

\begin{tabular}{|c|c|c|c|}
\hline Nombre & Fecha & Lugar & Descripción \\
\hline $\begin{array}{l}\text { Feria de las } \\
\text { Fresas }\end{array}$ & $\begin{array}{l}\text { Primera y } \\
\text { segunda } \\
\text { semana de } \\
\text { marzo. }\end{array}$ & $\begin{array}{l}\text { Irapuato, } \\
\text { Guanajuato }\end{array}$ & $\begin{array}{l}\text { Evento de realce en la capital mundial de las fresas. } \\
\text { Platillos tradicionales, eventos deportivos y } \\
\text { musicales, expos ganaderas y celebración } \\
\text { artesanal, todo en un mismo lugar. }\end{array}$ \\
\hline $\begin{array}{l}\text { Festival del Chile } \\
\text { en Nogada }\end{array}$ & $\begin{array}{l}\text { Todos los } \\
\text { domingos } \\
\text { de agosto. }\end{array}$ & Puebla & $\begin{array}{l}\text { Durante el mes de agosto, prácticamente todas las } \\
\text { ciudades del Estado se unen para mostrar la riqueza } \\
\text { de uno de los platillos más representativos de la } \\
\text { cocina mexicana. Todo esto acompañado de } \\
\text { exposiciones y talleres. }\end{array}$ \\
\hline $\begin{array}{l}\text { Gran Feria de la } \\
\text { Manzana }\end{array}$ & $\begin{array}{l}\text { Segunda } \\
\text { semana de } \\
\text { agosto. }\end{array}$ & $\begin{array}{l}\text { Zacatlán de } \\
\text { las } \\
\text { Manzanas }\end{array}$ & $\begin{array}{l}\text { Desde } 1834 \text {, este tradicional festejo se adueña del } \\
\text { pequeño pueblo mágico ubicado en la boscosa } \\
\text { cierra de puebla. Manzanas de todo tipo, desfiles } \\
\text { alegóricos, música y mucha sidra. }\end{array}$ \\
\hline $\begin{array}{l}\text { Feria Nacional del } \\
\text { Mole }\end{array}$ & $\begin{array}{l}\text { Todo el mes } \\
\text { de octubre. }\end{array}$ & $\begin{array}{l}\text { San Pedro } \\
\text { Actopan, } \\
\text { Cd Mx. }\end{array}$ & $\begin{array}{l}\text { Aproximadamente } 90 \text { toneladas de más de } 26 \\
\text { ingredientes se necesitan para darle vida a esta } \\
\text { feria. Además de los cocineros locales, miles de } \\
\text { restauranteros de todo México presentan una gran } \\
\text { variedad de platillos a base de distintos tipos de } \\
\text { mole. }\end{array}$ \\
\hline $\begin{array}{l}\text { Festival del } \\
\text { Chocolate }\end{array}$ & $\begin{array}{l}\text { Última } \\
\text { semana de } \\
\text { noviembre. }\end{array}$ & Tabasco & $\begin{array}{l}70 \text { ediciones llenas de conferencias, talleres, } \\
\text { concursos, recorridos y exposiciones respaldan al } \\
\text { Festival del Chocolate. }\end{array}$ \\
\hline $\begin{array}{l}\text { Festival Cultural } \\
\text { del Tequila }\end{array}$ & $\begin{array}{l}\text { Primer fin de } \\
\text { semana de } \\
\text { abril. }\end{array}$ & Tequila & $\begin{array}{l}\text { En un escenario considerado por la UNESCO como } \\
\text { "Patrimonio de la Humanidad", se reúnen } \\
\text { actividades culturales (danza, música, teatro) con } \\
\text { las diferentes etapas y variedades de la bebida } \\
\text { nacional por excelencia. }\end{array}$ \\
\hline
\end{tabular}




\begin{tabular}{|c|c|c|}
\hline $\begin{array}{l}\text { Festival } \\
\text { internacional de la } \\
\text { Cerveza }\end{array}$ & $\begin{array}{l}\text { Segundo fin } \\
\text { de semana } \\
\text { de mayo. }\end{array}$ & Morelia \\
\hline $\begin{array}{l}\text { Feria Internacional } \\
\text { del Mezcal }\end{array}$ & $\begin{array}{l}\text { Dos últimas } \\
\text { semanas de } \\
\text { julio. }\end{array}$ & Oaxaca \\
\hline $\begin{array}{l}\text { San Miguel } \\
\text { Gourmet }\end{array}$ & $\begin{array}{l}\text { Finales de } \\
\text { mayo a } \\
\text { principios de } \\
\text { junio }\end{array}$ & $\begin{array}{l}\text { San Miguel } \\
\text { de Allende. }\end{array}$ \\
\hline $\begin{array}{l}\text { Feria Nacional del } \\
\text { Queso y el Vino }\end{array}$ & $\begin{array}{l}15 \text { al } 31 \text { de } \\
\text { mayo. }\end{array}$ & $\begin{array}{l}\text { Tequisquia } \\
\text { pan }\end{array}$ \\
\hline
\end{tabular}

México con las manos

COME Festival Internacional de Sabores Jalisco

Festival "MXFEST Mayo y Estilo Bajaurbano"

Hokol Vuh

Encuentro de
Cocineras
Tradicionales de
Oaxaca

24 y 25 de Abril

Segundo fin Toluca
de semana
en Marzo

Primer fin de Guadalajar semana de a

Marzo

Junio

Feria del Téjate y
el Tamal

Cumbre

Internacional de Gastronomía

Festival Internacional del Vino CDMX, Guadalajar

a,

Veracruz, Oaxaca y Puebla

Del 19 al 24 Mérida de junio

Oaxaca de Juárez

Penúltima Oaxaca de semana de Juárez Julio

Del 30 de Mayo al 11 de Junio

Guanajuato
Más de 200 etiquetas nacionales e internacionales (en venta, exposición y degustación), así como stands gastronómicos, conferencias, y eventos que van de la música al fútbol.

Uno de los destinos más coloridos y espectaculares del país hace del centro de la ciudad un paraíso que combina las variaciones mezcaleras con las delicias gastronómicas del estado.

Múltiples eventos de primer nivel alrededor de la ciudad hacen de este festival uno de talla internacional.

El tercer pueblo mágico de la lista recibe cada año a los más exigentes amantes del vino, en donde disfrutan de catas, degustaciones y visitas guiadas a los principales ranchos y casas vitivinícolas de la región.

Degustación de comida callejera en una exposición que muestra la diversidad culinaria de todos los estados del país.

El principal objetivo, es el promover la gastronomía mexicana y se espera que asistan importantes chefs nacionales y extranjeros. Los asistentes tienen la posibilidad de participar de clases demostrativas, catas, degustaciones, cenas con maridaje, etc.

Restaurant Iniciativa que busca promover la cultura y el es de la consumo del vino mexicano en conjunto con la extraordinaria gastronomía de la región vinícola de Baja California.

Chefs a nivel mundial descubrirán la herencia Maya a través de la religión, espiritualidad, gastronomía, paisajismo, la caza y la pesca. De esta forma se reforzará ante el mundo la importancia de las raíces mexicanas, transportando a los invitados con cada ingrediente al origen de las civilizaciones.

Con la premisa de salvaguardar, preservar y difundir la grandeza gastronómica como patrimonio inmaterial del Estado de Oaxaca, la Coordinación de las Culturas, Turismo y Economía del Municipio de Oaxaca de Juárez en el marco del "Festejo a Oaxaca"

Aprovechando el marco de la celebración de la Guelaguetza, se realiza la Feria del Tejate y el Tamal donde se dan degustación y se exponen sus extensas variedades

Con la finalidad de seguir manteniendo la cultura tradicional gastronómica mostrando el orgullo, el sabor y las tradiciones del estado con deliciosos platillos hechos por cocineras tradicionales que viven en zonas rurales, pueblos mágicos y en diferentes municipios.

Cuenta con la participación de más de 100 bodegas nacionales e internacionales, además de un extenso programa de catas, talleres, conferencias y 


\begin{tabular}{|c|c|}
\hline $\begin{array}{l}\text { SMA Food } \\
\text { Festival }\end{array}$ & $\begin{array}{l}\text { Ultimo fin de } \\
\text { semana de } \\
\text { Junio }\end{array}$ \\
\hline
\end{tabular}

Festival Nacional del Pozole y el Mezcal

Feria del Café

Morelia en Boca

Cuarto Festival del
Chef Sonora
Feria Nacional de
la Enchilada

Encuentro de Cocineras Tradicionales de Morelos

Festival Gourmet Sabor es Polanco

Festival de las

Siete Cazuelas

Festival de chiles, salsas y molcajetes
Primer

domingo de

maño

durante 8

días

Del 29 de

abril al 15

de mayo

Tercer fin de Morelia semana de Mayo

\section{6 de Abril}

Semana de Pascua

mer fin de semana de Abril

13 de Abril

Arteaga

Coahuila

Ultimo

jueves a

Ciudad de domingo de Marzo

Coatepec Graciano Sánchez, San Luis Potos

Ciudad de México comidas y cenas maridaje impartidas por enólogos, propietarios y sommeliers de todas partes del mundo.

Una de las actividades que hacen destacar a este festival es "La Mesa del Chef", un evento en donde los chefs asistentes trabajan juntos por primera vez en equipos de 4 o 5 para preparar una comida a 26 comensales. Los asistentes también pueden degustar vinos, cerveza, comida y disfrutar de las artesanías expuestas.

Chilpancing Reúne a más de 40 pozolerías para así poder disfrutar de sus distintas variedades de pozoles acompañados por los tradicionales mezcales que se prepara en la región.

Una de las ferias más importantes del estado de Veracruz. Al asistir, además de encontrar a los mejores productores de café mexicano, tendremos la oportunidad de presenciar un encuentro de ballets folklóricos de México, un encuentro de arpa y jarana y otros entretenimientos culturales.

Un festival internacional de gastronomía y vino en México que no debemos perdernos. Es el punto de reunión de reconocidos chefs, cocineros y sommeliers nacionales e internacionales que deleitaran nuestro paladar con degustaciones, catas y cenas que prometen una increíble experiencia gastronómica.

Sonora Se dan cita reconocidos chefs internacionales y más de 100 expositores para deleitarnos con la mejor comida de Sonora y de México.

Soledad de Año con año se realiza la Feria Nacional de la Enchilada, donde encontramos un asombroso pabellón gastronómico y artesanal, además de eventos culturales.

Encuentro y concurso gastronómico para encontrar el mejor platillo tradicional, el mejor platillo de la milpa, el mejor de platillo de aprovechamiento, el mejor platillo ceremonial y el mejor platillo de rescate. Además de disfrutar de la cocina tradicional del estado, hay degustación de vino, mezcal y cerveza.

Es uno de los festivales gastronómicos más importantes de la Ciudad de México, es un recorrido por la oferta culinaria de los restaurantes más importantes de esta zona. Es el Campo Marte el que alberga a los amantes de la buena cocina para que disfruten con más de 950 platillos.

Se realiza en la explanada de la presidencia municipal. Un tradicional festival gastronómico donde podremos degustar los mejores platillos de la región.

Como cada año, en este festival podemos disfrutar de diversos talleres gastronómicos, conferencias, un concurso de salsas, exposición de chiles y molcajetes y disfrutar en esta ocasión de la cocina tradicional de un estado invitado y de cocina del mar. 


$\begin{array}{llll}\begin{array}{l}\text { Expo Repostería } \\ \text { Puebla }\end{array} & \begin{array}{l}\text { Segundo fin } \\ \text { de semana } \\ \text { de Julio }\end{array} & \text { Puebla } & \begin{array}{l}\text { El evento de repostería y panadería más } \\ \text { importante de la región donde se llevan a cabo } \\ \text { concursos, talleres, demostraciones }\end{array}\end{array}$

Fuente: Elaboración propia a partir de varias fuentes.

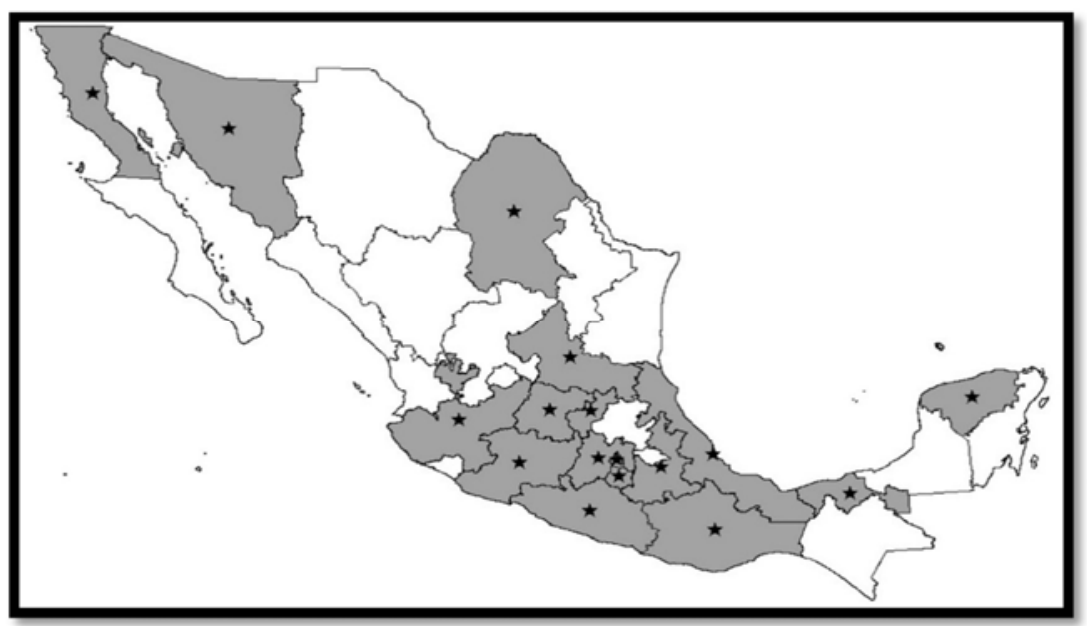

Figura 1. Representación geográfica de los eventos gastronómicos en México.

Fuente: Elaboración propia.

En la figura anterior, se puede observar que este tipo de actividades se desarrollan preferentemente en la región dentro y suroeste de la República Mexicana.

\section{DISCUSIÓN / CONCLUSIÓN}

La cocina mexicana es inigualable e inagotable, es producto de constantes mestizajes, pero sobre todo, resultado de la creatividad del mexicano y del gusto por prepararla, disfrutarla y compartirla.

Actualmente, se cohesiona con varias culturas, siendo las más significativas la española y la francesa. Los eventos gastronómicos son hoy en día componentes de productos turísticos en los diferentes Estados de México.

La gastronomía promueve en muchas personas el recuerdo y la evocación a la cultura, la tradición, de dónde se encuentran sus orígenes, entonces el turismo gastronómico como tal, le permite al viajero actual reconocer su cultura e identificarla, porque quiere tener la experiencia de un destino, pero además es irrepetible, ya el turista actual es cada vez menos repetible y fiel a los destinos, razón por la cual se debe atraer y provocar el retorno de los mismos, a través de otras experiencias. 
EVENTOS GASTRONÓMICOS EN MÉXICO Y TURISMO

Asimismo, los turistas gastronómicos tienen gastos medios elevados, por encima de los que presentan los turistas genéricos y por lo general cuentan con un nivel cultural elevado asociado a una buena situación económica. Generalmente, son poco sensibles a los precios, por lo cual se convierten en excelentes clientes de restaurantes, pues no se fijan en gastos para probar nuevos sabores, lo anterior como parte de la experiencia que buscan los visitantes o turistas actuales.

\section{CONSULTAS ELECTRÓNICAS}

http://cerveceriaallende.mx/eventos/10-festivales-gastronomicos-en-mexico-que-no-puedesperderte

http://lossaboresdemexico.com/mexico-las-manos-al-encuentro-la-cocina-callejera-del-pais/ http://lossaboresdemexico.com/festival-culinario-come-jalisco-todo-listo-para-su-terceraedicion/

http://lossaboresdemexico.com/festival-mxfest-incentivando-la-gastronomia-vinos-bajacalifornia/

http://lossaboresdemexico.com/hokol-vuh-el-evento-que-unira-a-los-mejores-chefs-delmundo-con-la-cultura-maya/

http://lossaboresdemexico.com/primer-encuentro-cocineras-tradicionales-oaxaca http://enmexico.about.com/od/Cultura-en-movimiento/tp/Viaje-Por-Los-FestivalesGastronomicos-De-Mexico.htm

https://www.directoalpaladar.com.mx/directo-al-paladar-mexico/agenda-gastronomica-enmexico-junio-de-2017

https://www.directoalpaladar.com.mx/directo-al-paladar-mexico/agenda-gastronomica-enmexico-junio-de-2017

https://www.directoalpaladar.com.mx/eventos/agenda-gastronomica-en-mexico-mayo-2017 https://www.directoalpaladar.com.mx/eventos/agenda-gastronomica-en-mexico-mayo-2017 https://www.directoalpaladar.com.mx/directo-al-paladar-mexico/agenda-gastronomica-enmexico-abril-2017

http://www.portalferias.com/expo-reposteria-puebla-2017_33437.htm 